OPEN ACCESS

Edited by:

Yahui Zhang,

Yanshan University, China

Reviewed by:

Peng Yong,

China Electric Power Research

Institute, China

Heming Deng,

Hubei University, China

*Correspondence:

Yuning Tao

taoyuning12@163.com

Specialty section:

This article was submitted to

Smart Grids,

a section of the journal

Frontiers in Energy Research

Received: 19 October 2021 Accepted: 02 November 2021 Published: 01 December 2021

Citation:

Fang C, Tao Y, Wang J, You H, Cui Y and Zhou M (2021) Research on Leakage Current Waveform Spectrum Characteristics of Artificial Pollution

Porcelain Insulator.

Front. Energy Res. 9:798048. doi: 10.3389/fenrg.2021.798048

\section{Research on Leakage Current Waveform Spectrum Characteristics of Artificial Pollution Porcelain Insulator}

\author{
Chunhua Fang ${ }^{1}$, Yuning Tao ${ }^{1 *}$, Jianguo Wang ${ }^{2}$, Haixin You ${ }^{1}$, Yan Cui ${ }^{1}$ and Mi Zhou ${ }^{2}$ \\ ${ }^{1}$ College of Electrical Engineering and New Energy, China Three Gorges University, Yichang, China, ${ }^{2}$ School of Electrical \\ Engineering, Wuhan University, Wuhan, China
}

The surface discharge development processes of polluted porcelain insulators for power transmission lines are tightly related with the development of leakage current (LC), the characteristics of LC, the insulating condition, and discharge intensity of the insulator surface have an important significance for revealing the contamination discharge state of insulators. In order to analyze the LC characteristics of porcelain insulators in the process of pollution flashover, artificial pollution flashover tests on porcelain insulators were conducted in the artificial fog cabinet, and the characteristics of LC waveforms in timedomain and frequency-domain were simultaneously measured and analyzed during the tests. The results indicated that the amplitude of LC, fundamental harmonic, the third harmonic, and fifth harmonic had a strong correlation, the maximum of $\mathrm{LC}\left(\mathrm{I}_{\mathrm{m}}\right)$, the rate of total harmonics $(T H D)$, and the phase difference of fundamental harmonic $(\theta)$ were used for the representation of the characteristics of the LC waveform. The LC has the characteristics of high amplitude, low proportion harmonic, and small phase difference between the fundamental harmonic and voltage before the flashover occurrence. The test results provide effective reference for porcelain insulators in pollution flashover forecasting.

Keywords: leakage current, insulator, pollution flashover, flashover voltage, transmission line

\section{INTRODUCTION}

Outdoor insulators have been exposed in severe environment since the birth of the power system (Yang et al., 2019; Liu et al., 2020; Shen and Raksincharoensak, 2021a; Shen and Raksincharoensak, 2021b). The airborne particles are deposited on the insulator surface and the pollution builds up gradually, which causes insulator flashover during wet weather conditions (Yang et al., 2019; Shen et al., 2021; Yang et al., 2021). So conditions monitoring of the insulator are important to know about insulator status of the insulator. The analysis of surface LC is necessary to know about the insulator condition (Miyake et al., 2010; Shen et al., 2020; Yang et al., 2020; Zhu et al., 2020; Noman et al., 2021).

A large number of research studies have dealt with LC, including the maximum value of the LC pulse under the operating voltage, the amplitude of the LC before the occurrence of flashover and the LC root-mean-square values (Li et al., 2010; Jiang et al., 2010). Besides, the number of the highest peak power-spectrum is also used as methods for pollution monitoring (Chandrasekar et al., 2009; Pylarinos et al., 2011; Pylarinos et al., 2012). Literature (Chaou et al., 2015) reported that the main frequency of the porcelain insulator LC waveform is 50,150 , and $250 \mathrm{~Hz}$ and the LC waveform is 


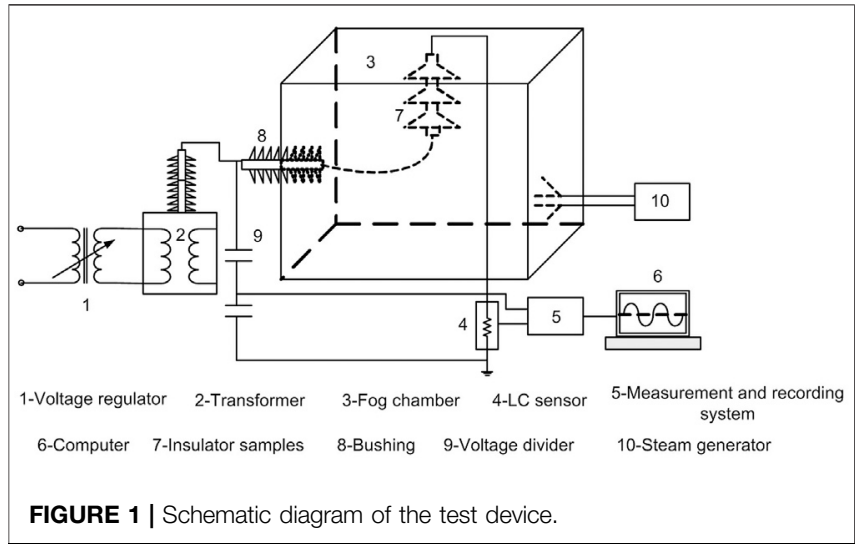

divided into six categories. Papers (Suda T, 2001; Bashir and Ahmad, 2010; Douar et al., 2010; Dhahbi-Megriche and Beroual, 2016) introduced the analysis of the variation characteristics of the LC in the frequency domain power spectrum during the entire process of the contamination flashover. But all these studies listed have not yet reached consensus on which spectrum parameters can represent contamination insulator surface state.

In this paper, while measuring polluted porcelain insulator LC data and shooting discharge pictures, the frequency spectrum characteristics of LC waveform is extracted during loading voltage process, analyzing the variation of LC characteristics carefully under various salt density, as well as the correlation between each feature quantity.

\section{EXPERIMENTAL EQUIPMENT AND METHOD}

\section{Experimental Equipment}

According to IEC60507 standard (IEC 60507, 1991), the solid layer method experiments are carried out in an artificial fog chamber. The schematic diagram of the test device is shown in Figure 1. The artificial fog chamber's dimensions are $5 \times 5 \times 5 \mathrm{~m}$. The power supply includes a shifting coil voltage regulator $(150 \mathrm{kV} / 4 \mathrm{~A})$ and test transformer $(1000 \mathrm{kV} / 2250 \mathrm{kVA})$. The high voltage supply is connected to the artificial fog chamber through a $220 \mathrm{kV}$ wall bushing. The fog is generated by the automatic steam generator. Steam output remains at a fixed rate. The data acquisition system monitors and records LC and voltage waveforms using a LABVIEW program on the personal computer. The leakage current sensor is connected to the lowvoltage circuit, the leakage current signal is obtained and the voltage signal is obtained through the capacitive voltage divider, which are then connected to the leakage current and voltage measurement system through the double-layer shielded coaxial cable, the sampling rate is $125 \mathrm{kS} / \mathrm{s}$, and then connected to the computer, the software of the leakage current measurement system finally completes the measurement of the leakage current and the pollution flashover voltage in the artificial pollution flashover test of the insulator.
TABLE 1 | Dimensions of test porcelain insulator.

\section{Parameters}

Maximum diameter

Creepage distance

Axial height
Dimensions in $\mathrm{mm}$

\section{Insulator Sample}

The XP-70 porcelain insulator is used to measure the LC in the test. A sample insulator string includes seven pieces of porcelain insulator that are used for the experiments. The details of the dimensions of the porcelain insulator are in Table $\mathbf{1}$.

\section{Test Methods}

The solid layer method as described in IEC60507 is used in the test (IEC, 1991). NaCl is used as soluble salt. Kaolin powder is used as non-soluble salt. First, $\mathrm{NaCl}$ is mixed with Kaolin powder in a certain proportion in distilled water. Then the mixture is coated on the clean porcelain insulator surface. Finally, the precontaminated samples are hung in the laboratory until they naturally dry for more than $24 \mathrm{~h}$ before the experiment. Based on the IEC60507 standard, four levels of equivalent salt deposit density $(E S D D)$ are applied to the experiment, respectively, 0, 0.1, 0.2 , and $0.4 \mathrm{mg} / \mathrm{cm}^{2}$. And the non-soluble deposit density (NSDD) is set to $1.0 \mathrm{mg} / \mathrm{cm}^{2}$. The commonly used methods of artificial pollution test include constant pressure lifting method. During the test, when the wetness of the umbrella skirt surface reaches a fully saturated state, the pressure is immediately increased to flashover. The speed of the increase is not specified before $40 \%$ of the expected flashover voltage. Then the voltage is increased to flashover at a rate of $10-20 \%$ of the expected flashover voltage per second.

\section{RESULTS AND DISCUSSION}

\section{Discharge Image and LC Waveforms and Frequency Spectrum}

As shown in Figure 2, at the first stage of discharge, the weak filamentary discharge can be seen on the surface of the porcelain insulator. With the increase of voltage, the "squeak" sound can be heard.

Contaminant forms a layer on the surface of the insulator in combination with water, which causes the formation of conducting films, and that causes to flow the LC through the insulator surface under wet conditions. Evaporation of water layers in these areas forms dry bands. The appearance of dry bands on the insulator surface causes arcs. Such arcs may elongate until they bridge the two metal electrodes of the insulator, and total flashover occurs.

With the increase of voltage, partial arcs will enter into a stage of stability. Blue-violet partial arcs will appear on the surface of the porcelain insulator. For the whole insulator string, the development of partial arcs of each piece of porcelain insulator is relatively independent. 

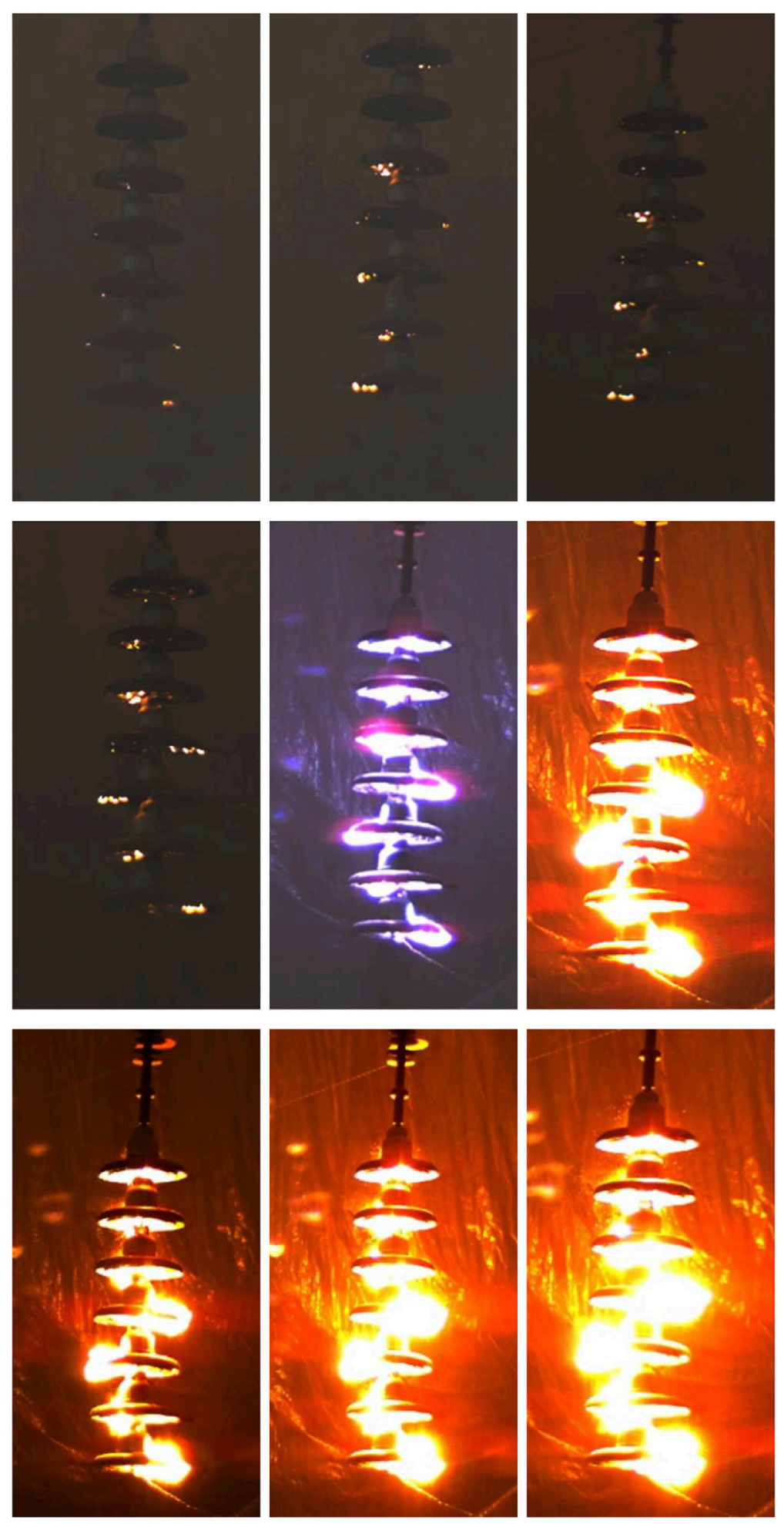

FIGURE 2 | The process of contamination discharge of insulators.

Bright blue-violet arcs are changed into light yellow, while the bright arcs are rotated around the axis of the porcelain insulator. A large number of small arcs get together to form the main arc and develop along the surface of the insulator. As voltage continues to increase, the partial arcs have a tendency to through the surface of an insulator, when they cross $70 \%$ 

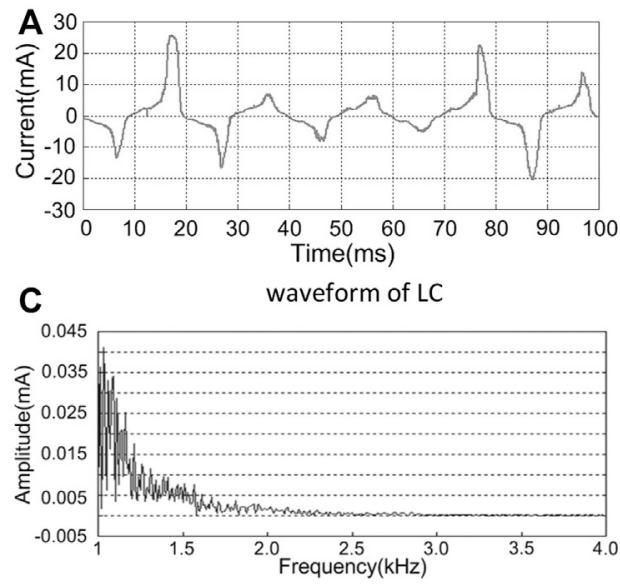

1-4 kHz

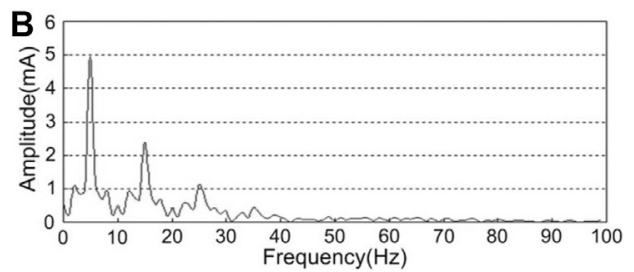

D

$0-100 \mathrm{~Hz}$

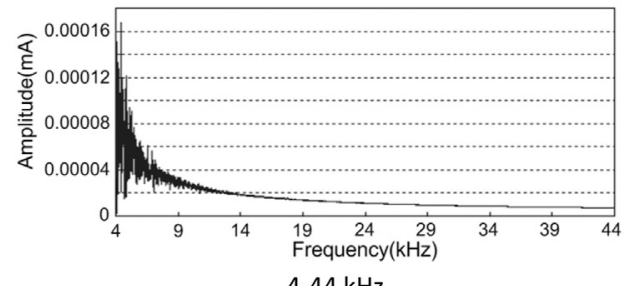

$4-44 \mathrm{kHz}$

FIGURE 3 | The LC waveform and its Fourier transform.

creepage distance of the insulator, porcelain insulator string flashover.

Figure 3A shows a typical waveform of LC obtained at the test. Figures 3B-D show the frequency spectrum of Figure 3A. The frequency components of LC were studied within $0-100 \mathrm{~Hz}$, $1-4$, and $4-44 \mathrm{kHz}$. With the increase of frequency, the amplitude of LC decreases gradually. The maximum value of $\mathrm{LC}$ at $1 \mathrm{kHz}$ is only $0.04 \mathrm{~mA}$, which is more than that at $1.5 \mathrm{kHz}$. The amplitude of LC is less than $0.005 \mathrm{~mA}$. It is only $0.1 \%$ of the fundamental harmonic. In Figure 3A, it is obvious that there is the third, fifth, and seventh harmonics, especially the third and fifth harmonics, expect the amplitude of the fundamental harmonic at $50 \mathrm{~Hz}$.

A typical LC waveform and corresponding spectrum graph are shown in Figure 4. When the porcelain insulator surface is dry or extremely low contamination degree, there is LC waveform in Figure 4A. The waveform is a sine wave, but the phase difference is larger between the voltage and the fundamental harmonic, some even meet to $90^{\circ}$. When the insulator surface appears weak discharge current slowly, the LC waveform begins to distortion into symmetrical triangle waveform (Figure 4B), the odd harmonic increases sharply; when the discharge becomes more obvious and intense, the triangle wave will significantly increase, the peak of the LC waveform becomes more prominent, an asymmetric waveform is formed (Figure 4C); the strong arcs almost across insulator string before flashover occurs. The characteristics of LC are mainly decided by the nature of the arcs, a long arc represents resistance. As shown in Figure 4D, resistive current will appear again, but the amplitude of LC will increase tens to hundreds of $\mathrm{mA}$.

\section{LC Characteristic}

The change curves of applied voltage and LC of porcelain insulator under different salt density are shown in Figure 5. With the increase of voltage, LC increases linearly, when the voltage rises to a certain value, the amplitude of LC begins to fluctuate, the value of salt density is higher, the discharge becomes more powerful and intense. The amplitude of LC increases sharply before the flashover is coming.

\section{THD Variation Law of Polluted Insulators Under Wet Conditions}

THD is the total harmonic distortion of LC (Khodsuz and Mizaie, 2015). The change curve of THD during loading voltage process is shown in Figure 6. The curve of THD of a clean insulator is shown in Figure 6A, the initial applied voltage is small, the LC of a clean insulator is also small, the interfering signals cause higher distortion. With the increase of voltage, the LC increases, the value of THD decreases gradually; a small number of arcs appear on the surface of the porcelain insulator. THD increases suddenly before the flashover is coming. As shown in Figures 6B,C, when the salt density is 0.1 , and $0.2 \mathrm{mg} / \mathrm{cm}^{2}, T H D$ changes greatly after the pressure for more than $20 \mathrm{~s}$. With the salt density increased to $0.4 \mathrm{mg} / \mathrm{cm}^{2}$, THD changes more intensely.

\section{Phase Angel $\theta$ of Polluted Insulators LC Variation Law Under Wet Conditions}

The $\theta$ is the phase difference between the applied voltage and LC. Change curves of phase difference under different salt densities are shown in Figure 7. The LC phase of clean porcelain insulators decreased gradually with the voltage increased, which decreased from 75 to $20^{\circ}$. The phase difference was mutated into a negative value before flashover occurs, which shows that there is a big arc, and following with insulator flashover.

LC contains resistive current and capacitive current, the proportion of resistive current is different from capacitive current, so the phase difference fluctuates between the positive and negative. With the increase of voltage, the porcelain insulator surface does not appear to discharge, the phase difference gradually decreases to negative, then the insulator begins to violently discharge and the phase difference begins to flounce between positive and negative. 

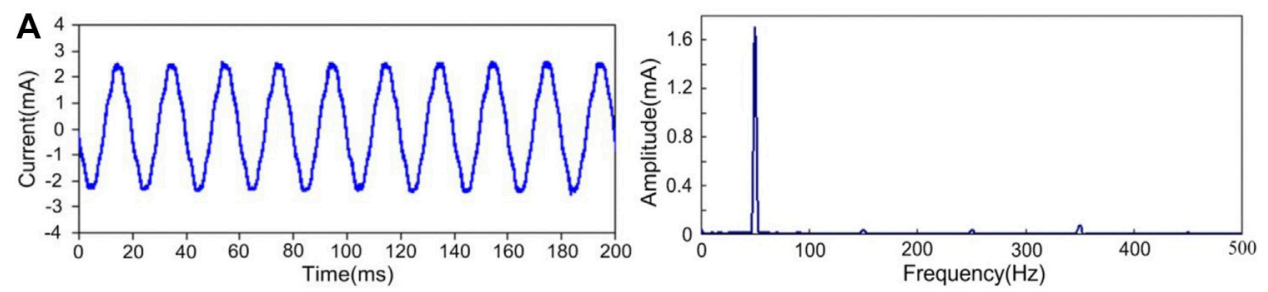

B
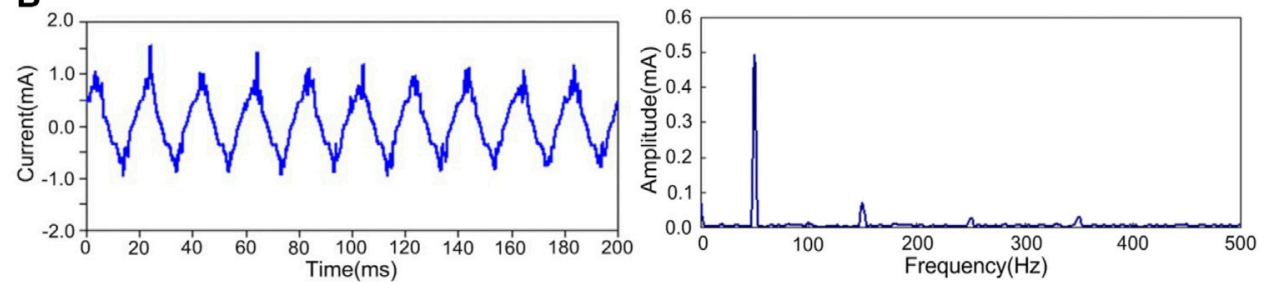

C

Waveform and spectrum 2
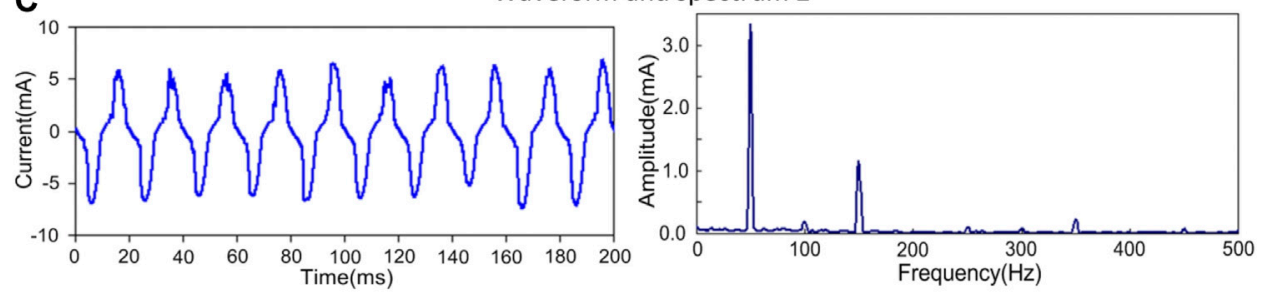

D

Waveform and spectrum 3
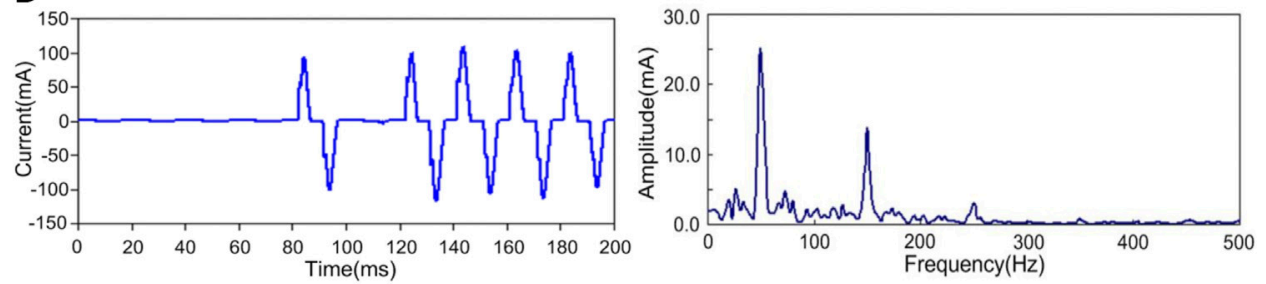

Waveform and spectrum 4

FIGURE 4 | LC waveforms and frequency spectrum of different discharging strength.
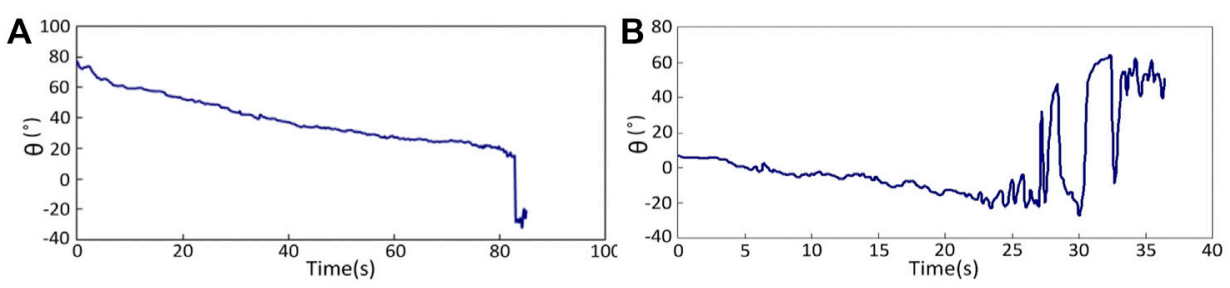

C

Clean insulator

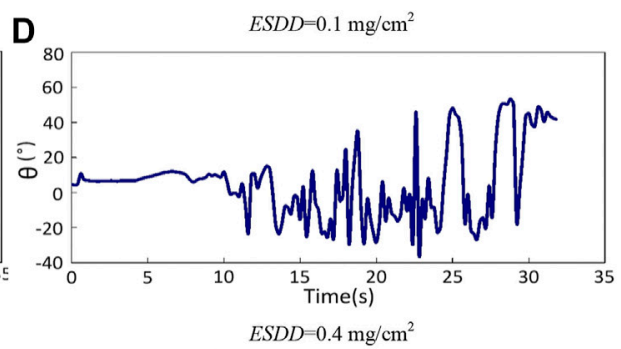

FIGURE $\mathbf{5}$ | Curves of LC with the increasing voltage. 

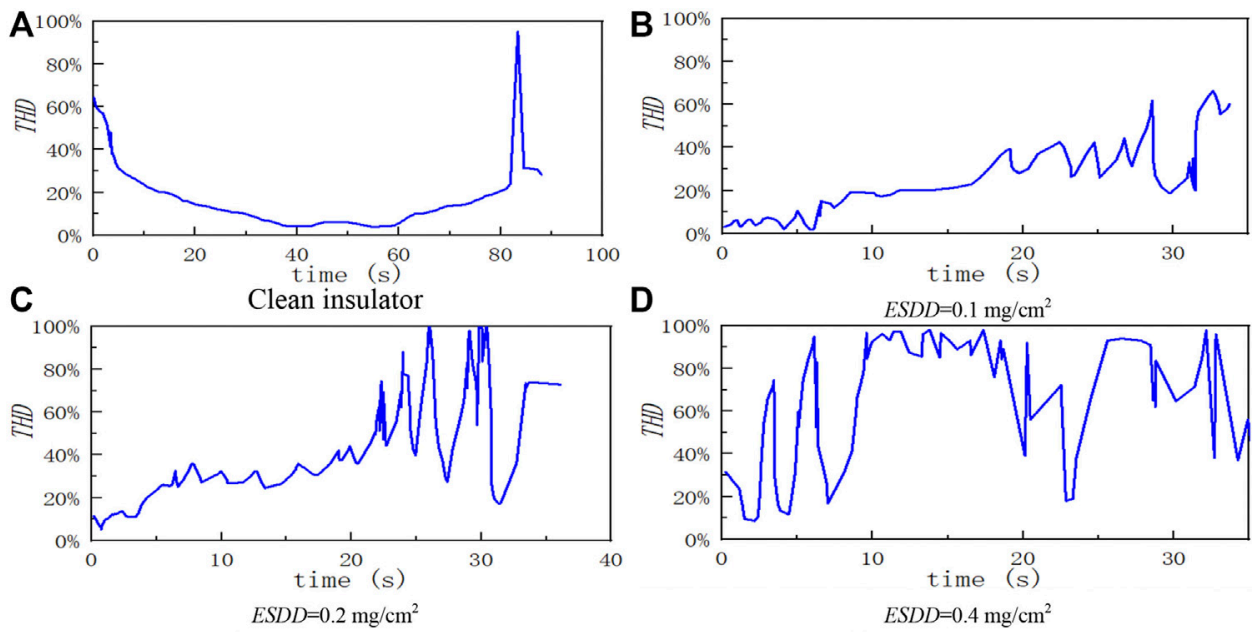

FIGURE 6 | Curves of THD of insulators under different pollution conditions.
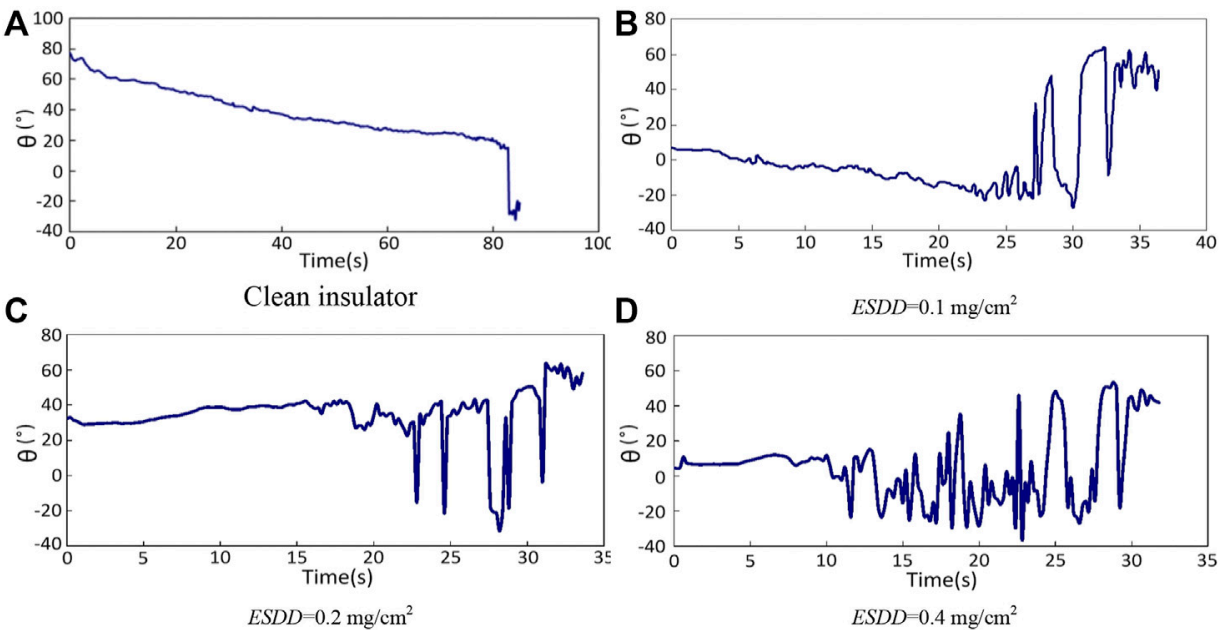

FIGURE 7 | Curves of $\theta$ of LC under different ESDD.

TABLE 2 | The coefficient of LC eigenvalues on clean insulator.

\begin{tabular}{lcccccc} 
& $\boldsymbol{I}_{\mathbf{m}}$ & $\boldsymbol{I}_{\mathbf{1 m}}$ & $\boldsymbol{I}_{\mathbf{3 m}}$ & $\boldsymbol{I}_{\mathbf{5 m}}$ & $\boldsymbol{\theta}$ & $\boldsymbol{T H D}$ \\
\hline$I_{\mathrm{m}}$ & 1.000 & 0.908 & 0.998 & 0.998 & -0.229 & 0.418 \\
$I_{1 \mathrm{~m}}$ & 0.908 & 1.000 & 0.928 & 0.886 & -0.461 & 0.285 \\
$I_{3 \mathrm{~m}}$ & 0.998 & 0.928 & 1.000 & 0.994 & -0.252 & 0.431 \\
$I_{5 \mathrm{~m}}$ & 0.998 & 0.886 & 0.994 & 1.000 & -0.197 & 0.425 \\
$\theta$ & -0.229 & -0.461 & -0.252 & -0.197 & 1.000 & 0.249 \\
$T H D$ & 0.418 & 0.285 & 0.431 & 0.425 & 0.249 & 1.000
\end{tabular}

\section{The Relationship LC Characteristics}

LC fundamental harmonic, the third harmonic, the fifth harmonic, and the rate of total harmonic and the phase difference of the fundamental harmonic has carried on the correlation analysis.
TABLE 3 | The coefficient of LC eigenvalues $\left(E S D D=0.1 \mathrm{mg} / \mathrm{cm}^{2}\right)$.

\begin{tabular}{lcccccc} 
& $\boldsymbol{I}_{\mathbf{m}}$ & $\boldsymbol{I}_{\mathbf{1 m}}$ & $\boldsymbol{I}_{\mathbf{3 m}}$ & $\boldsymbol{I}_{\mathbf{5 m}}$ & $\boldsymbol{\theta}$ & $\boldsymbol{T H D}$ \\
\hline$I_{\mathrm{m}}$ & 1.000 & 0.971 & 0.865 & 0.917 & -0.491 & -0.061 \\
$I_{1 \mathrm{~m}}$ & 0.977 & 1.000 & 0.802 & 0.881 & -0.402 & -0.162 \\
$I_{3 \mathrm{~m}}$ & 0.865 & 0.804 & 1.000 & 0.958 & -0.597 & -0.021 \\
$I_{5 \mathrm{~m}}$ & 0.917 & 0.887 & 0.957 & 1.000 & -0.565 & -0.072 \\
$\theta$ & -0.494 & -0.407 & -0.594 & -0.564 & 1.000 & 0.094 \\
$T H D$ & -0.061 & -0.162 & -0.022 & -0.075 & 0.094 & 1.000
\end{tabular}

From Table 2 to Table 3, the correlation coefficient between the amplitude of LC and fundamental harmonic, the third harmonic, and the fifth harmonic is more than 0.800 . The amplitude of the LC can be used to represent the fundamental wave, third, and fifth harmonic; current amplitude has a low 
TABLE 4 | The coefficient of LC eigenvalues (ESDD $\left.=0.2 \mathrm{mg} / \mathrm{cm}^{2}\right)$.

\begin{tabular}{lcccccc}
\hline & $\boldsymbol{I}_{\mathbf{m}}$ & $\boldsymbol{I}_{\mathbf{1 m}}$ & $\boldsymbol{I}_{\mathbf{3 m}}$ & $\boldsymbol{I}_{\mathbf{5 m}}$ & $\boldsymbol{\Theta}$ & $\mathbf{T H D}$ \\
\hline$I_{\mathrm{m}}$ & 1.000 & 0.969 & 0.861 & 0.934 & -0.620 & 0.121 \\
$I_{1 \mathrm{~m}}$ & 0.969 & 1.000 & 0.823 & 0.924 & -0.490 & 0.042 \\
$I_{3 \mathrm{~m}}$ & 0.861 & 0.823 & 1.000 & 0.938 & -0.701 & $0.158^{*}$ \\
$I_{5 \mathrm{~m}}$ & 0.934 & 0.924 & 0.938 & 1.000 & -0.655 & 0.135 \\
$\theta$ & -0.620 & -0.490 & -0.701 & -0.655 & 1.000 & 0.012 \\
$T H D$ & 0.121 & 0.042 & $0.158^{\star}$ & 0.135 & 0.012 & 1.000 \\
\hline
\end{tabular}

TABLE 5 | The coefficient of LC eigenvalues (ESDD $\left.=0.4 \mathrm{mg} / \mathrm{cm}^{2}\right)$.

\begin{tabular}{lcccccc} 
& $\boldsymbol{I}_{\mathbf{m}}$ & $\boldsymbol{I}_{\mathbf{1 m}}$ & $\boldsymbol{I}_{\mathbf{3 m}}$ & $\boldsymbol{I}_{\mathbf{5 m}}$ & $\boldsymbol{\theta}$ & $\boldsymbol{T H D}$ \\
\hline$I_{\mathrm{m}}$ & 1.000 & 0.919 & 0.901 & 0.845 & -0.368 & $-0.173^{*}$ \\
$I_{1 \mathrm{~m}}$ & 0.919 & 1.000 & 0.823 & 0.887 & -0.204 & -0.240 \\
$I_{3 \mathrm{~m}}$ & 0.901 & 0.823 & 1.000 & 0.965 & -0.430 & -0.155 \\
$I_{5 \mathrm{~m}}$ & 0.845 & 0.887 & 0.965 & 1.000 & -0.444 & -0.101 \\
$\theta$ & -0.368 & -0.204 & -0.430 & -0.444 & 1.000 & -0.383 \\
$T H D$ & $-0.173^{*}$ & -0.240 & -0.155 & -0.101 & -0.383 & 1.000
\end{tabular}

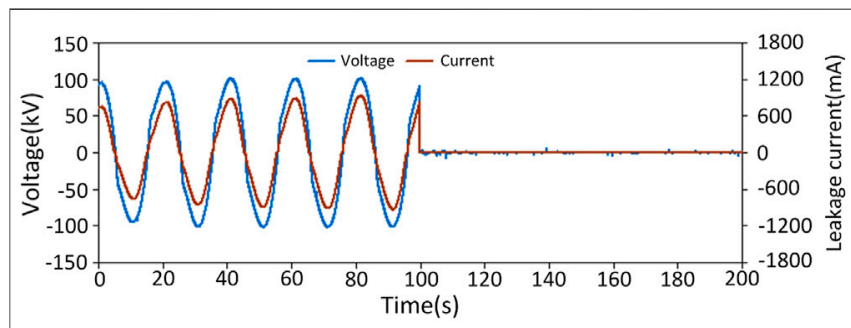

FIGURE $\mathbf{8}$ | The voltage and current waveform of flashover.

correlation with $\theta$, the maximum value is only -0.620 under four pollution levels, and all are negative. It is indicated that the value of LC is bigger. That $\theta$ is smaller; the correlation of THD and current amplitude is less than 0.44. Distortion degree of LC waveform and the value of LC lack of a strong linear relationship; there is no significant correlation between THD and $\theta$.

The maximum value of $\mathrm{LC}$ is affected by the degree of pollution. The THD represents the degree of distortion of the $\mathrm{LC}$ waveform; the phase difference can distinguish effectively capacitive current and resistive current. Three characteristics describe the situation of LC of porcelain insulator surface from different aspects. The waveform of LC can be characterized by three features that are current amplitude, THD, and phase difference.

\section{The LC Characteristics Before Flash}

As shown in Figure 8, when the flashover occurs on the surface of the porcelain insulator, the voltage drops to zero rapidly. Before the flashover, the LC did not increase sharply, arcs almost throughout the whole string of the insulator, which lasted for a long time. The waveform of LC and applied voltage is shown in Figure 9, NSDD is $1.0 \mathrm{mg} / \mathrm{cm}^{2}, E S D D$ is $0.1,0.2,0.4 \mathrm{mg} / \mathrm{cm}^{2}$, the amplitude of LC reached more than $700 \mathrm{~mA}$ before flashover. The

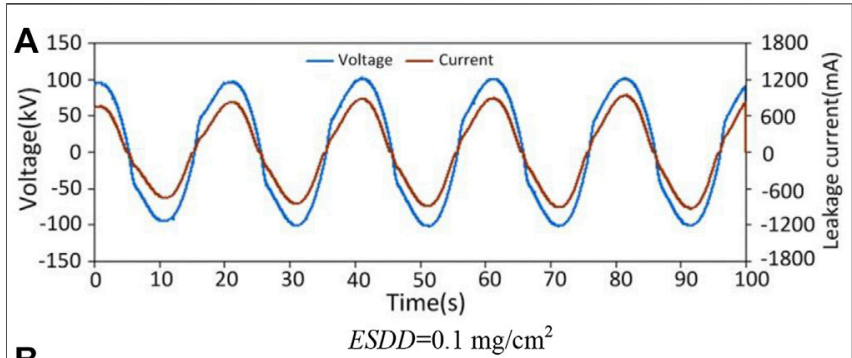

B

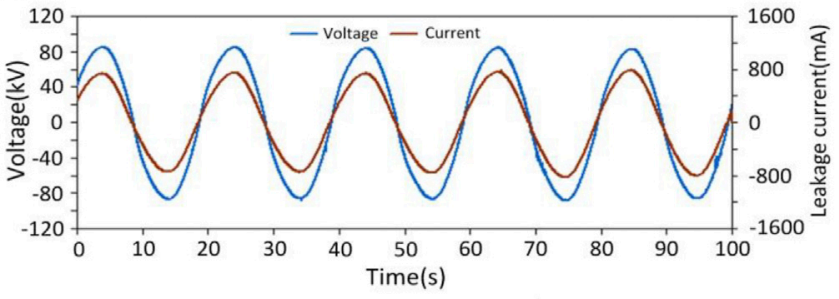

C

$E S D D=0.2 \mathrm{mg} / \mathrm{cm}^{2}$

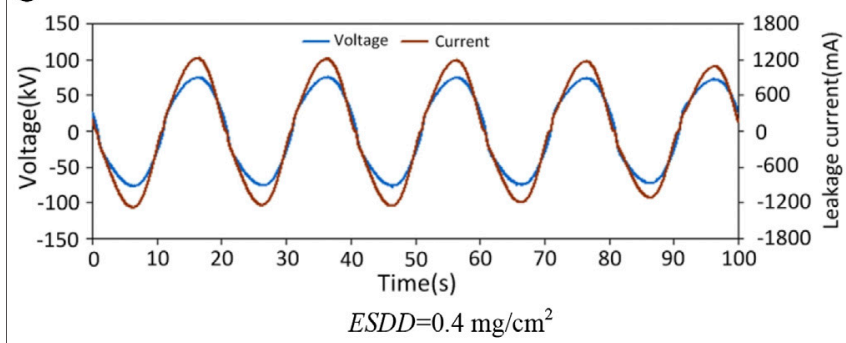

FIGURE 9 | The voltage and current waveform of pre-flashover.

total harmonic and phase differences are small, and the LC mainly is resistive current.

\section{CONCLUSION}

1) The correlation coefficient between the amplitude of LC and fundamental harmonic, the third harmonic, and the fifth harmonic is more than 0.800 ; the amplitude of the LC can be used to represent the fundamental waveform, the third harmonic, and the fifth harmonic; the correlation of THD and maximum value of $\mathrm{LC}$ is less than 0.44 ; the distortion degree of the LC waveform and the value of LC lack of a strong linear relationship; there is no significant correlation between $T H D$ and $\theta$.

2) The maximum value of LC is affected by the degree of pollution. The THD represents the degree of distortion of LC waveform; the phase difference can distinguish effectively capacitive current and resistive current. Three characteristics describe the situation of LC of porcelain insulator surface from different aspects. The waveform of $\mathrm{LC}$ can be characterized by three features that are current amplitude, $T H D$, and phase difference.

3) Test results can be used as an effective reference for porcelain insulators in pollution flashover forecasting. 


\section{DATA AVAILABILITY STATEMENT}

The raw data supporting the conclusions of this article will be made available by the authors, without undue reservation.

\section{AUTHOR CONTRIBUTIONS}

C.F., J.W., and H.Y. conceived the idea and designed the experiments. C.F. and H.Y. led the experiments. Y.T., Y.C.,

\section{REFERENCES}

Bashir, N., and Ahmad, H. (2010). Odd Harmonics and Third to Fifth Harmonic Ratios of Leakage Currents as Diagnostic Tools to Study the Ageing of Glass Insulators. IEEE Trans. Dielect. Electr. Insul. 17 (3), 819-832. doi:10.1109/ TDEI.2010.5492255

Chandrasekar, S., Kalaivanan, C., Cavallini, A., and Montanari, G. (2009). Investigations on Leakage Current and Phase Angle Characteristics of Porcelain and Polymeric Insulator under Contaminated Conditions. IEEE Trans. Dielect. Electr. Insul. 16 (2), 574-583. doi:10.1109/ TDEI.2009.4815193

Chaou, A. K., Mekhaldi, A., and Teguar, M. (2015). Recurrence Quantification Analysis as a Novel LC Feature Extraction Technique for the Classification of Pollution Severity on HV Insulator Model. IEEE Trans. Dielect. Electr. Insul. 22 (6), 3376-3384. doi:10.1109/TDEI.2015.004921

Dhahbi-Megriche, N., and Beroual, A. (2015). Time-frequency Analyses of Leakage Current Waveforms of High Voltage Insulators in Uniform and Non-uniform Polluted Conditions. IET Sci. Meas. Tech. 9 (8), 945-954. doi:10.1049/ietsmt.2015.0116

Douar, M., Mekhaldi, A., and Bouzidi, M. (2010). Flashover Process and Frequency Analysis of the Leakage Current on Insulator Model under Non-uniform Pollution Conditions. IEEE Trans. Dielect. Electr. Insul. 17 (4), 1284-1297. doi:10.1109/TDEI.2010.5539701

IEC (1991). Artificial Pollution Tests on High-Voltage Insulators to Be Used on A.C. Systems, IEC 60507. Available at: https://webstore.iec.ch/publication/ 16401.

Jiang, X., Shi, Y., Sun, C., and Zhang, Z. (2010). Evaluating the Safety Condition of Porcelain Insulators by the Time and Frequency Characteristics of LC Based on Artificial Pollution Tests. IEEE Trans. Dielect. Electr. Insul. 17 (2), 481-489. doi:10.1109/TDEI.2010.5448104

Khodsuz, M., and Mirzaie, M. (2015). Harmonics Ratios of Resistive Leakage Current as Metal Oxide Surge Arresters Diagnostic Tools. Measurement 70, 148-155. doi:10.1016/j.measurement.2015.03.048

Li, J., Caixin Sun, C., Wenxia Sima, fnm., Qing Yang, fnm., and Jianlin Hu, fnm. (2010). Contamination Level Prediction of Insulators Based on the Characteristics of Leakage Current. IEEE Trans. Power Deliv. 25 (1), 417-424. doi:10.1109/TPWRD.2009.2035426

Liu, Y., Yang, N., Dong, B., Wu, L., Yan, J., Shen, X., et al. (2020). Multi-Lateral Participants Decision-Making: A Distribution System Planning Approach with Incomplete Information Game. IEEE Access 8, 88933-88950. doi:10.1109/ ACCESS.2020.2991181

Miyake, T., Seo, Y., Sakoda, T., and Otsubo, M. (2010). Relationship between Leakage Current and Pollution Deposits on the Surface of Polymeric Insulator. IEEJ Trans. FM 130 (11), 1037-1041. doi:10.1541/ieejfms.130.1037

Noman, M., Li, G., Wang, K., and Han, B. (2021). Electrical Control Strategy for an Ocean Energy Conversion System. Prot. Control. Mod. Power Syst. 6 (1), 12. doi:10.1186/s41601-021-00186-y

Pylarinos, D., Siderakis, K., and Pyrgioti, E. (2011). Measuring and Analyzing Leakage Current for Outdoor Insulators and Specimens. Rev. Adv. Mater. Sci. 29 (1), 31-53. doi:10.2217/NNM.11.108 and M.Z. contributed to data analysis and interpretation. C.F. and Y.T. wrote the paper. All authors read and approved the final manuscript.

\section{FUNDING}

This paper is supported by the National Natural Science Foundation of China (Grant No. 51807110).

Pylarinos, D., Theofilatos, K., Siderakis, K., Thalassinakis, E., Vitellas, I., Alexandridis, A. T., et al. (2012). Investigation and Classification of Field Leakage Current Waveforms. IEEE Trans. Dielect. Electr. Insul. 19, 2111-2118. doi:10.1109/TDEI.2012.6396971

Shen, X., Ouyang, T., Khajorntraidet, C., Li, Y., Li, S., and Zhuang, J. (2021). Mixture Density Networks-Based Knock Simulator. Ieee/asme Trans. Mechatron., 1. doi:10.1109/TMECH.2021.3059775

Shen, X., and Raksincharoensak, P. (2021b). Pedestrian-aware Statistical Risk Assessment. IEEE Trans. Intell. Transport. Syst., 1-9. doi:10.1109/ TITS.2021.3074522

Shen, X., and Raksincharoensak, P. (2021a). Statistical Models of Near-Accident Event and Pedestrian Behavior at Non-signalized Intersections. J. Appl. Stat., 1-21. doi:10.1080/02664763.2021.1962263

Shen, X., Zhang, Y., Sata, K., and Shen, T. (2020). Gaussian Mixture Model Clustering-Based Knock Threshold Learning in Automotive Engines. Ieee/asme Trans. Mechatron. 25, 2981-2991. doi:10.1109/TMECH.2020.3000732

Suda, T. (2001). Frequency Characteristics of Leakage Current Waveforms of an Artificially Polluted Suspension Insulator. IEEE Trans. Dielect. Electr. Insul. 8 (4), 705-709. doi:10.1109/94.946726

Yang, N., Huang, Y., Hou, D., Liu, S., Ye, D., Dong, B., et al. (2019). Adaptive Nonparametric Kernel Density Estimation Approach for Joint Probability Density Function Modeling of Multiple Wind Farms. Energies 12, 1356. doi:10.3390/en12071356

Yang, N., Liu, S., Deng, Y., and Xing, C. (2020). An Improved Robust SCUC Approach Considering Multiple Uncertainty and Correlation. IEEJ Trans. Elec Electron. Eng. 16 (1), 21-34. doi:10.1002/tee.23265

Yang, N., Yang, C., Wu, L., Shen, X., Jia, J., Li, Z., et al. (2021). Intelligent DataDriven Decision-Making Method for Dynamic Multi-Sequence: An E-Seq2Seq Based SCUC Expert System. IEEE Trans. Ind. Inf. 40, 1. doi:10.1109/ TII.2021.3107406

Zhu, B., Ding, F., and Vilathgamuwa, D. M. (2020). Coat Circuits for DC-DC Converters to Improve Voltage Conversion Ratio. IEEE Trans. Power Electron. 35, 3679-3687. doi:10.1109/TPEL.2019.2934726

Conflict of Interest: The authors declare that the research was conducted in the absence of any commercial or financial relationships that could be construed as a potential conflict of interest.

Publisher's Note: All claims expressed in this article are solely those of the authors and do not necessarily represent those of their affiliated organizations, or those of the publisher, the editors, and the reviewers. Any product that may be evaluated in this article, or claim that may be made by its manufacturer, is not guaranteed or endorsed by the publisher.

Copyright (c) 2021 Fang, Tao, Wang, You, Cui and Zhou. This is an open-access article distributed under the terms of the Creative Commons Attribution License (CC $B Y)$. The use, distribution or reproduction in other forums is permitted, provided the original author(s) and the copyright owner(s) are credited and that the original publication in this journal is cited, in accordance with accepted academic practice. No use, distribution or reproduction is permitted which does not comply with these terms. 